\title{
Special Needs of Elderly in Using Web-Based Services
}

\author{
Konsta Rantakangas ${ }^{1}$, and Raija Halonen ${ }^{1}$ \\ ${ }^{1}$ University of Oulu, M3S, Oulu, Finland, Finland \\ postierantakangas.com \\ raija.halonen@oulu.fi
}

\begin{abstract}
The number of elderly is growing also in Finland. As the traditional services are decreasing and net based services are developed, also the elderly need to adapt the new services. However, the elderly have special needs compared to the younger generation, and they need to be considered when designing net services. This study responded to two research problems. First, the special needs of elderly were considered. Second, the special needs of elderly were approached from the developers' point of view. A light literature review was applied to find state-of-the-art knowledge.
\end{abstract}

Keywords: Elderly · Web-based Services · Special Needs.

\section{$1 \quad$ Introduction}

In the recent past years, different web-based services enabled by information and communication technology (ICT) have become ever more significant in everyday life. However, their efficient and practical utilization is not familiar for all potential users. Elderly people are one of such users who have special needs related to web-based services, and their special needs should be considered when designing those services. [1] Especially young adults and middle-aged persons have benefited from modern Internet-based services offered by banks and public service providers. However, the elderly have noticed it more difficult when carrying their tasks because service providers have decreased their traditional ways to offer services. [2],[3].

Along with ageing sight, hearing and sense of touch get worse. In addition, skills related to read, listen and understand guidelines based on trying get weaker. E.g. using mouse gets more difficult due to declined motoric ability and declined memory leads to difficulty to remember all steps when navigating in an online service process. [4]

The way fonts, colour, pictures, search and navigation are tasks that can make net based services too challenging to apply by elderly [5]. On the other hand, proper planning and development allow designers to build systems with suitable usability also for elderly [6]. Checklists help web designers to ensure that their web pages are suitable also for elderly people. However, several studies have shown that the checklists do not guarantee a usable web page even if all criteria mentioned in the checklist are filled. [7]

Most people over 65 years have experience of using ICT [4]. The living experiences of elderly have influenced their later use of web-based services and building ICT competences [7] and ever more elderly have later got familiarised with e.g. social media such as Facebook and modern ICT-based device like smart phones [8].

The current study analysed how to design different web-based services especially 
when regarding elderly people who have special needs as users of the services to offer information for the designers to be used in building web-based services, and that the new services would be simple and easy especially for the elderly [9],[6].

The research problem was approached with the next research questions: What kind of special needs do elderly people have as users of web-based services? How should developers design such web-based services that would support elderly with special needs?

The study was based on earlier knowledge, and it was limited to concentrate on elderly people as users of web-based services and who have special needs, which makes use of web-based services difficult or makes it impossible. Furthermore, as the study was carried out as a light literature review, it acts as a mirror of what has been reported about elderly and their potential special needs elated to using web-based services.

The paper continues as follows: First, the study applying literature review is reported. Second, the results of the study are briefly discussed. The paper ends with conclusions and proposal for a thorough study.

\section{The Study}

This section introduces the research approach in its first section. After that, the special needs of the elderly are described and potential special features in web-services are considered, and conclusions of the highlights of the review are presented at the end.

\subsection{Research Approach}

The current theoretical-based study was carried out as a light literature research. The literature for the study was searched by using Google Scholar and the background idea was to find out what is known in general from elderly people and their age-related needs as users of web-based services. To start, relevant keywords for the search were listed starting with concepts of web usability, HCI, human computer interaction, guidelines, web development. The elderly as users were searched with concepts like senior citizen, senior, older people, older adults, and elderly.

\subsection{Special Needs of Elderly as Users of Web-based services}

When talking the speed of using web-based services, elderly people are generally slower than younger adults. It also takes longer time to choose or locate points and sections in the web page such as links to next pages. This is due to weakening sight, the large amount of information on the page, and decreasing skills of cognitive skills. [10] However, even if elderly might be slower than younger adults, they do less mistakes than the younger people [11]. Even if elderly are often slower readers than younger people because they have sight issues, they also are pedantic users of web-based services [7].

Sight is a significant doer that makes it more challenging for elderly people to utilise web-based services. With ageing, sight gets weaker in many ways related to such as differing acuity and distinguishing contrasts and amount of light [5],[12] Kantner and Rosenbaum [13] highlighted the role of own weakening seeing skill as an obstacle in 
using web-based services. In addition, elderly people can see lousy placement or design of push buttons too challenging. Too coloured or in general confusing colours can lead the users to get annoyed. [1] Another problem is related to the font size of the screen if users don't know how to change it, and if the fonts on the keyboard are too small, it also adds difficulties [12],[13]

Hearing issues get more serious among most people when getting old. The problems can be minimised if the tones and informative comments are loud enough and in a proper frequency rate for the elderly. Hearing issue is the most annoying problem in discussions in both face-to-face and net based discussions. [1],[12]

When the motoric skills slowly weaken, moving pointers and choosing and pushing small buttons get more challenging than before [1],[5],[12]. In addition, rolling the mouse can be difficult for the elderly. The younger generation need significantly less time to act with pointers compared to the elderly [5]. This can lead to situations when the elderly are afraid to use the pointers because they try to avoid making mistakes with the pointers [1],[12].

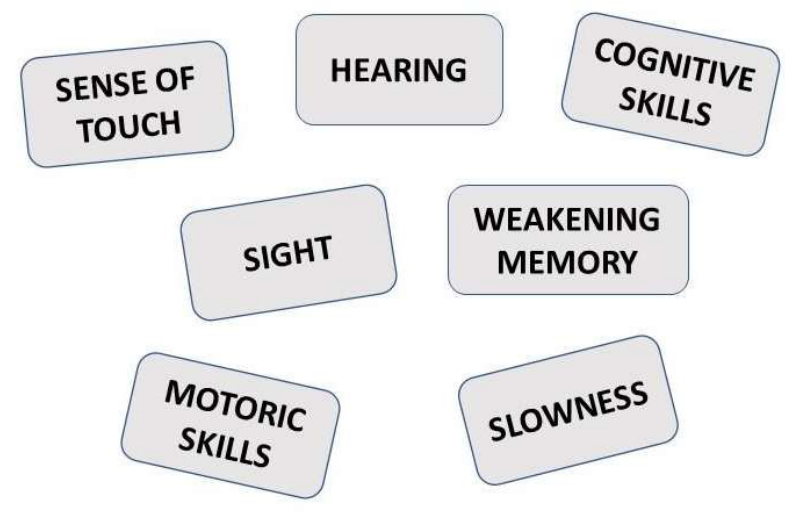

Fig. 1. Elderly special matters related to ageing.

Tsai and Lee [14] proposed that the elderly will soon use touch screens when navigating in the web-based services. However, sense of touch can be weakened due to high age, and the elderly might have unintentional double keystrokes [1]. In addition, some of the devices with touch pads do not give sufficient feedback after a successful selection of function, and the users do not know that. Therefore, the users can make additional selections in the web-based services and it can lead to such unintended choices that were not even noted during the session. [1],[14]

With ageing, the skills to solve problems, remember tasks and pay attention to things. This can lead to situations when the elderly cannot learn, remember or perceive the structure of web pages of the web-based services in cases the pages are not designed keeping in mind their elderly users. [5] For example, navigating forth and back can be challenging if the user does not remember how she or he entered to the current page [1]. Along with decreasing cognitive skills, also weakening memory makes it harder to figure out navigating and structures of web pages [10]. Figure 1 illustrates the special 
matters that need to be understood when considering elderly people and their different competences. Studies have also shown that especially building search strings is seen challenging in general [13]. On the other hand, too much information on the web page can make the use of net service too challenging for the elderly. The elderly need more time to identify the important information among all available information and it takes more time for them. [10] Especially commercial web-based services are perceived threatening, obscuring and messy by the elderly [6].

\subsection{Considering Special Needs in Web-based Services}

Elderly people with worsening sight prefer text-based net pages that utilize large fonts and that include only little graphics. The elderly perceive such pages friendlier to use than other kinds of net pages. [11] Another more pleasant feature in web-based services are simple looking net pages where the choosing buttons are large enough. Furthermore, 'back and forward' buttons should be located so that they are always easy to find. The elderly also see that popup windows cause mixing feelings because the elderly find it challenging to return to the earlier view. [13] On the other hand, the usability of webbased services does not always improve significantly if the font size is larger. However, the elderly saw it more pleasant to use web pages with larger font [7].

When the sense of touch weakens along aging the application developers face new challenges how to inform the elderly users that they have managed to choose their next action by pushing successfully the relevant button. In case the sense of touch is weak it is not reasonable to apply haptic touch because the users receive no feedback with their decreased sense of touch. This challenge can be won with a special feature called icon feedback that aims to visualise what has happened after the user touched the button. [14] In addition, including a sound signal such as a cling or honk as a mark of a successful action to the users to inform that the users can focus on a pop-up message on the screen [1]

The motoric skills should be supported by including possibilities to use both a mouse and keyboard [1]. The user interface should be designed in a way that allows the elderly users to use it without experiencing significant challenges when focusing the pointer to desired locations on the screen and thus decrease difficulties perceived by elderly when scrolling the mouse on a small object [12]. In addition, increasing the size of icons and buttons on the web pages would make it easier to use the system. Double-clicks should be replaced with one-click elements and use of mouseover should be minimised [5].

Figure 2 illustrates the consequences that emerge when the users are getting older. As verified by earlier knowledge, the elderly prefer text-based pages to graphic-based pages, the benefit from clear feedback when the icons appear or disappear, and they prefer simple outlook and axiomatic appearance of pages and contents to more sophisticated appearance. 


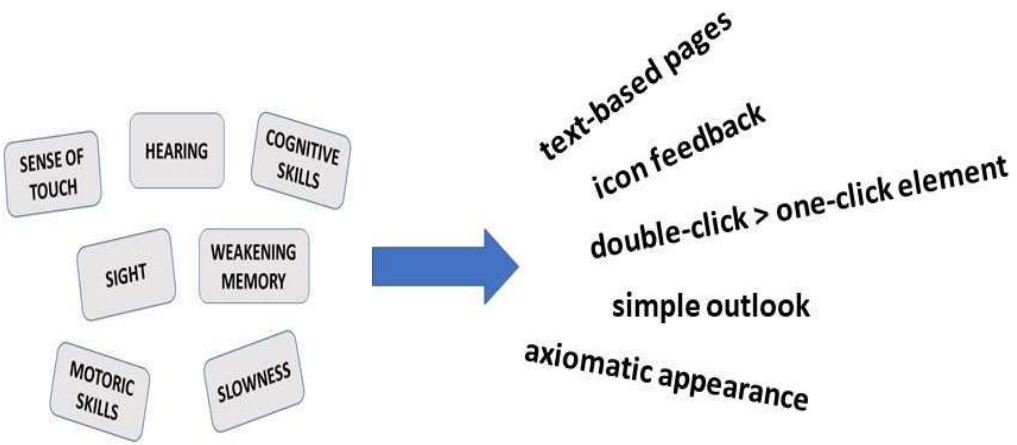

Fig. 2. Consequences of ageing.

To support versatile users in finding information they are searching, the web-based services should understand natural sentences such as 'Where can I change my password?' [1]. The extensive amount of information on a web page can make it too challenging to find and select the required choice. To reduce this challenge more practicing with navigating has been suggested, as active use of web-based services has more positive influence on learning navigation than age [15]. To avoid the extensive amount of information and its disorientating nature the web-based services should appear distinct and axiomatic, without additional elements such as graphic animations that can draw the elderly's attention. If the users experience several announcements disturbing the general information and announcements could be placed a defined section on the screen to reduce their annoying visibility. [1] In general, the developers should favour simplicity and plainness and keep the number of versatile announcements from the web service in minimum [10]

To find out the skills of future or potential users for using web-based services, the developers should perform a test that would evaluate the level of experience of the users related to the web-based services. The test can be carried out with the help of a questionnaire. Questions to ask focus on such as purposes to use the services, use experiences, needed functionalities and length of being a net service user. However, a more efficient way to analyse the skills could be to find out what the users does in the services, what they think when they use the services, and how they feel when they use the services. Chadwick-Dias et al. [16] concluded that the developers should focus more on the usage patterns and qualitative web experience of the users that would reveal how users learn using web-based services.

The developers could build a functionality into the web services that could produce a general user profile according to the user. The functionality could include a brief and easy-to-answer questionnaire to adjust the settings to fit with each user. The questionnaire could find out the state of sight, hearing, memory, and motoric skills, and it should happen quickly enough. Based on that information, the system would automatically change font-size, loud-speakers and other user features to fit that user. 
There are guidelines to support usability especially for elderly users. The idea of guidelines is to make it easier for developers to develop web services for elderly if the developers have knowledge and checklists of requirements and features related to elderly users. Generally, the guidelines give information about navigating, explicit content expression and general output of the web services. However, the guidelines do not include information about specific sizes for fonts or pushbuttons. [4],[10],[19] Besides applying the guidelines, it is significant to invite the elderly to participate in developing the web services. In this sense, the guidelines can act as a starting point for the development and commit elderly into the development work, which makes the development more efficient.[9]

Guidelines and support should offer such information that it would not contain too complicated and difficult technical terms and concepts. All technical terms should be replaced by corresponding terms that are far enough from the original terms [1]. In addition, the amount of complicated technical terms should be as small as possible to avoid extra learning load when a person is practicing using web-based services [17]. In general, positive experiences in using web-based services improves skills and motivation to learn to use other information systems and web-based services [18].

\subsection{Summary of Earlier Knowledge}

In all, it is important to consider the elderly people when developing services for them. They also form the population group that will grow quickly compared to other age groups. Elderly people have special needs that affect their lives and ways how they use available services. Especially in case of neglect design and development of web-based services and webpages, the elderly experience challenges to adopt and apply the offered services. Therefore, it is important to invite and commit also elderly people into the development process and projects to ensure that the products are beneficial and meet their intentions.

For the elderly, choosing desired sections or locating points on the screen takes longer time caused by weakened sight, too extensive amount of information on the page, and decreasing skills of cognitive skills. [1],[5],[10],[12],[13]. However, as they understand their age-related decreased skills, the elderly pay more attention to their actions on the web pages than their younger counterparts, which makes them meticulous users of the services. [7].

Earlier knowledge also revealed that the earlier experiences and skills related to ICT and web-based services encourage and help the elderly to learn to use new and different web-based services. Despite that, the number of technical concepts and terms are often perceived as confusing and adding concern among the elderly. Moreover, navigating and hyper links add challenges to use the services. Keeping this in mind, the developers should be aware of the challenges the elderly meet and use the knowledge when designing and developing new web-based solutions and services.

\section{Discussion}

The current study focused on two research questions: What kind of special needs do elderly people have as users of web-based services? How should developers design 
such web-based services that would support elderly with special needs? This section discusses the research topic from three points of view. First, a general approach is taken, that is followed by a section of special needs of the elderly as users of web-based services, and finally the special needs of elderly as users of web-based services are considered.

\subsection{General Discussion}

The first research question about special needs of elderly people related to web-based services could be responded with the help of earlier knowledge that the special needs of the elderly are related to slowness, sight, hearing, motoric skills, sense of touch, cognitive skills, memory, general technical skills and differing earlier experiences of using devices with information technology and web-based services. The second research question was answered by several guidelines and earlier reports how developers do consider the special needs of elderly and how they could pay more attention to the special needs.

Weakened sight can be a challenge [13] as it makes reading from different sized screens difficult especially if there are lots of text and guidelines to be understood. Other challenges are related to loss of motoric skills that affect ability to use pointers and make desired choices among several push buttons or links [1],[5],[12]. When their memories weaken, the elderly perceive difficulties to comprehend and learn the page structure and thus also navigating is difficult [5]. In addition, earlier experiences have a significant impact on the skills and readiness of the elderly to use web-based services, which suggest that special needs can and should be supported by choices made by the developers. Such choices are related to, for example, using larger fonts, stronger contrast, and non-intrusive background of text that would not impede reading [1],[5]. The weakened motoric skills could be noted by reducing need to use pointer between small items but instead, using larger push buttons and items to be pointed [12]. To reduce issues related to loss of memory, the navigating model should be clear and explicit and thus support the users whose memory and cognitive skills are weakened [5].

\subsection{Special Needs of the Elderly as Users of Web-Based Services}

Slowness is identified as one of the special characters of elderly as users of net that should be noted when designing services for them. The issues are emphasized especially with services that utilize timeout in the process. For example, when identifying users to register into banking services that also the elderly need it adds challenges in the use process. [10] Another concern is related to sight because a weakened sight needs to be noted and considered when designing potentially additional features into the application [13].

Besides poorly situated and unpractical push buttons, also issues with colours make the elderly feel uncomfortable to use web-based services. Small buttons and almost ]. similar coloured than the background are difficult to find and identify.[1],[13] In addition, when hearing gets worse, the auditive signs get more challenging to be heard by the elderly [12]. However, not all web-based services apply auditive signs anymore. Only in case there is no visual information available, hearing should be considered with 
more care. [1].

Along with reducing motoric skills choosing small elements on the screen comes more challenging. This can lead to making more mistakes and further cause additional problems when the elderly will not use the services due to being afraid of doing mistakes, and then, the elderly might reduce ever more usage of web-based services and will lead them not to learn and comprehend new and needed web-based services. [12]

Another issue characteristic for elderly is decreased sense of touch that makes it more difficult to identify if the current touch lead to a desired function in the application, because the user can be unaware of the state of the system. Did the touch affect anything or not remains unknown. On the other hand, the number of unintended double touches increases remarkably, which also should be understood by the developers and responded in the design and implementation of the related functionalities.[1]

Skills to solve problems, working memory and observing get weaker when the elderly are getting their later years of age, and that has an influence on ability to navigate and find relevant choices and buttons in the web-based services. These problems are connected with searching information with the help of building search strings and comprehending functional processes of the current service. The most evident cause for the problems is due to limited memory and cognitive skills of the elderly. [13] In addition, too much of visible information is a known problem especially in commercial web-based services [6],[10]. Figure 3 illustrates the main needs of the elderly users of web-based services as reported by earlier studies.
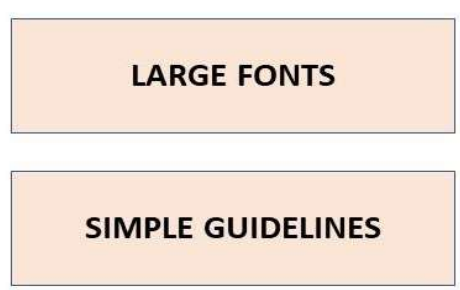

LITTLE COLOURS

STRONG CONTRASTS

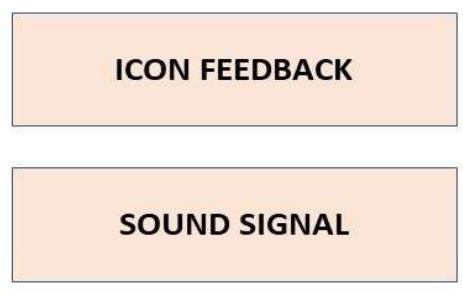

MOUSE \& KEYBOARD

\section{LARGE ICONS/BUTTONS}

Fig. 3. Needs of the elderly.

Most elderly are familiar with personal computers but not all have experience of internet [4]. Most elderly also consider their skills to apply web-based services [13]. Also, they are afraid of making mistakes [15]. The problems emerge especially in 
situations when the elderly have no means to carry their tasks on site due to physical or other disabilities. In those cases, web-based services could be the best solution. However, if the elderly are afraid of using web-based services, and the dilemma can lead to expensive or difficult problems to solve. Therefore, the elderly and the challenges they perceive should be treated with care and seek for means to encourage and help them in using web-based services. [7]

\subsection{Supporting Special Needs in Web-Based Services}

The elderly like more text-based web-based services than services that include lots of graphics [11]. Therefore the developers should consider improving web-based services that include only little additional graphics and that appear as simple as possible [13]. Text with sharp contrast and well separating background is a recommended way to ease the elderly who need the web-based services [1]. Because sense of touch and hearing get often worse as perceived by the elderly, the elderly can find it challenging to note that they already had made their choice for the next activity e.g. choosing a specific button or option in the service. This challenge was responded by applying icon feedback into the services. In practice, icon feedback utilizes visual features to inform the success of made choices [14] Another assisting choice is to avoid applying mouseover that reduces the need to use mouse as a pointer between the push buttons. In addition, double clicks are not suitable for the elderly users [5].

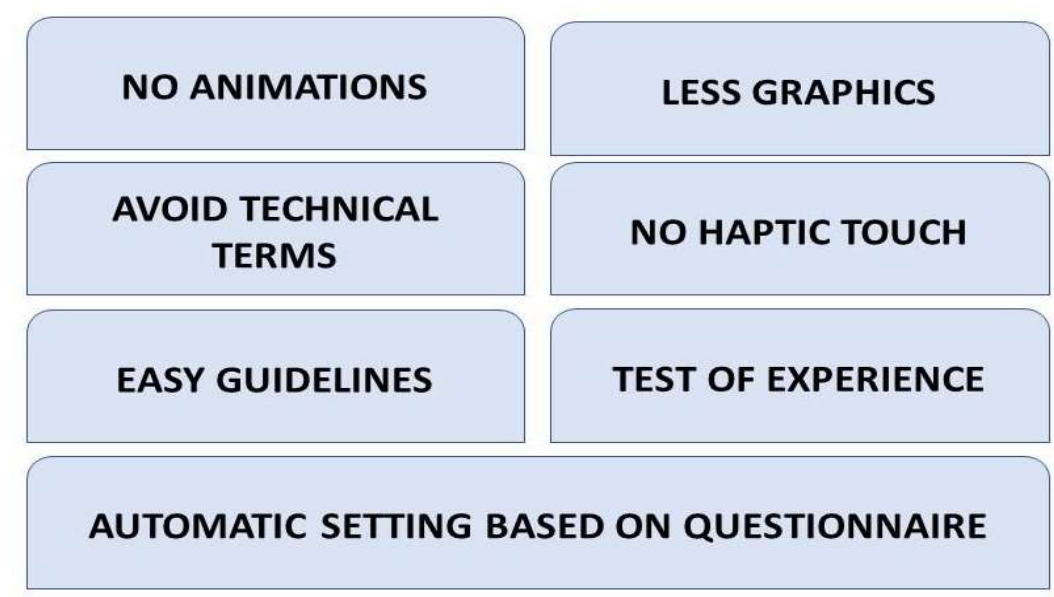

Fig. 4. Building blocks to be used by developers.

Figure 4 illustrates the building blocks to be used by developers when they design and build web-based services for elderly people. The blocks could point out such approaches and experiences that are not as familiar to developers representing younger generations than to the elderly users who will form the actual user group of the webbased services.

In addition, a special search field should be available on the pages to allow natural search strings written by the users, because if the cognitive skills are getting humbler, 
the users see it difficult to build search strings for themselves [1]. Earlier studies have shown that aged people form a group that is not homogenous when regarding their technological skills. This knowledge leads to suggesting that developers should offer assistance and support in a way that can be requested when using the web-based services [17]. Furthermore, the elderly should be encouraged to use and utilize different web-based services despite challenges they might experience, as only getting more practice and experiences will add praxis and knowledge, and thus reduce uncertainty and ambivalence in using the services [18]. However, a good conclusion is to remember that technology should adjust according to the users' needs and not the other way round [9].

\section{Conclusion}

The current research problem was related to the thought that the elderly people are not enough taken into account when designing several web-based services even if the group of elderly people forms a large user group for services, which was identified by earlier knowledge and visible also everyday lives of many of us. They cannot be included into any other user group that consists of people significantly younger than they are as ageing brings challenges that need to be considered when designing services. Earlier knowledge has revealed that most of the elderly experience similar challenges when they use the traditional services [13].

The literature review was pretty light in nature, it managed to identify several special characteristics of the elderly caused by high age or diagnosed reasons such as memoryrelated diseases. Similarly, the literature review revealed potential ways to mitigate the challenges the elderly face when using web-based services. This paper paid attention especially on the means and knowledge that the developers and designers of web-based services already have and could apply when building services for the elderly.

The topic of elderly people applying web-based services could be continued among elderly and focus on analysing how they experience the current available web-based services and what they expect from them. As the current knowledge has shown, the amount of elderly is increasing, and they will be applying more web-based services because they have been using them for decades - however, due to issues emerging due to ageing they will need special solutions to continue in applying them.

In addition, the future study could offer knowledge of the IT skills of the elderly and analyse if and how they have changed in time. While analysing the IT skills of the elderly, also the modern solutions could be evaluated and analysed if they develop the same pace as the skills of elderly do. Moreover, it would be interesting to know when the gap between the earlier sufficient skills and abilities is getting too large for a reasonable use of web-based services as perceived by the elderly.

\section{References}

1. Williams, D., Alam, M. A. U., Ahamed, S. I., Chu, W.: Considerations in designing humancomputer interfaces for elderly people. 2013 13th International Conference on Quality Software, s.372-377 (2013). 
2. Pollitt, C.: Technological Change: a central yet neglected feature of public administration. NISPAcee Journal of Public Administration and Policy, 3(2), 31-53. https://doi.org/10.2478/v10110-010-0003-z (2010).

3. Koiranen, I., Räsänen, P., Södergård, C.: Mitä digitalisaatio on tarkoittanut kansalaisen näkökulmasta? Talous ja yhteiskunta, 3/2016, 24-29 (2016).

4. Dickinson, A., Arnott, J., Prior, S.: Methods for human-computer interaction research with older people. Behaviour \& Information Technology, 26(4), 343-352 (2007).

5. Becker, S. A.: A study of web usability for older adults seeking online health resources. ACM Transactions on Computer-Human Interaction, 11(4), 387-406 (2004).

6. Newell, A. F.: HCI and older people. HCI and the Older Population. 10.2638728.2641558 (2004).

7. Chadwick-Dias, A., McNulty, M., Tullis, T.: Web usability and age: how design changes can improve performance. ACM SIGCAPH Computers and the Physically Handicapped, 73-74, 30-37 (2003).

8. Mikkola, K., Halonen, R.: "Nonsense?" - ICT perceived by the elderly. European, Mediterranean \& Middle Eastern Conference on Information Systems (EMCIS 2011) May 30-31, Athens, Greece. http://emcis.eu/Emcis_archive/EMCIS/EMCIS2011/EMCISWebsite/EMCIS2011\%20Proc eedings/SCI1.pdf (2011).

9. Castilla, D., Garcia-Palacios, A., Bretón-López, J., Miralles, N., Baños, R., Etchemendy, E., Farfallini, L., Botella, C.: Process of design and usability evaluation of a telepsychology web and virtual reality system for the elderly: Butler. International Journal of HumanComputer Studies, 71(3), 350-362 (2013).

10. Hart, T. A., Chaparro, B. S., Halcomb, C. G.: Evaluating websites for older adults: adherence to 'senior-friendly' guidelines and end-user performance. Behaviour \& Information Technology, 27(3), 191-199 (2008).

11. Liao, C., Goff, L., Chaparro, A., Chaparro, B., Stumpfhauser, L.: A comparison of website usage between young adults and the elderly. Proceedings of the Human Factors and Ergonomics Society Annual Meeting, 4, 101 (2000).

12. Chen, Y.: Usability analysis on online social networks for the elderly. TKK T-110.5190 Seminar on Internetworking. Helsinki University of Technology (2009).

13. Kantner, L., Rosenbaum, S.: Usable computers for the elderly: applying coaching experiences. IEEE International Professional Communication Conference, (2003).

14. Tsai, W. C., Lee, C. F.: A study on the icon feedback types of small touch screen for the elderly. International Conference on Universal Access in Human-Computer Interaction, s.422-431 (2009).

15. Loos, E.: Senior citizens: Digital immigrants in their own country? Observatorio (OBS*), 6(1) (2012)

16. Chadwick-Dias, A., Tedesco, D., Tullis, T.: Older adults and web usability: iweb experience the same as web expertise? CHI'04 extended abstracts on human factors in computing systems, s.1391-1394 (2004).

17. Naumanen, M., Tukiainen, M.: Guiding the elderly into the use of computers and InternetLessons taught and learnt. Proceedings of cognition and exploratory learning in digital age, s.19-27 (2007).

18. Czaja, S. J., Sharit, J.: Age differences in attitudes toward computers. The Journals of Gerontology Series B: Psychological Sciences and Social Sciences, 53(5), 329-340 (1998).

19. Hart, T. A., Chaparro, B.: Evaluation of Websites for Older Adults: How" Senior Friendly" are they. Usability News, 6(1), 12 (2004). 